\title{
Regional Supply of Chiropractic Care and Visits to Primary Care Physicians for Back and Neck Pain
}

\author{
Matthew A. Davis, MPH, DC, PhD, Olga Yakusheva, PhD, Daniel J. Gottlieb, MS, \\ and Julie P.W. Bynum, MD, MPH
}

Background: Whether availability of chiropractic care affects use of primary care physician (PCP) services is unknown.

Methods: We performed a cross-sectional study of 17.7 million older adults who were enrolled in Medicare from 2010 to 2011. We examined the relationship between regional supply of chiropractic care and PCP services using Spearman correlation. Generalized linear models were used to examine the association between regional supply of chiropractic care and number of annual visits to PCPs for back and/or neck pain.

Results: We found a positive association between regional supply of chiropractic care and PCP services $\left(r_{\mathrm{s}}=0.52 ; P<.001\right)$. An inverse association between supply of chiropractic care and the number of annual visits to PCPs for back and/or neck pain was apparent. The number of PCP visits for back and/or neck pain was $8 \%$ lower (rate ratio, $0.92 ; 95 \%$ confidence interval, $0.91-0.92$ ) in the quintile with the highest supply of chiropractic care compared to the lowest quintile. We estimate chiropractic care is associated with a reduction of 0.37 million visits to PCPs nationally, at a cost of $\$ 83.5$ million.

Conclusions: Greater availability of chiropractic care in some areas may be offsetting PCP services for back and/or neck pain among older adults. (J Am Board Fam Med 2015;28:481-490.)

Keywords: Back Pain, Complementary Medicine, Primary Health Care

In recent years, health care visits for back and neck pain have increased substantially, with annual expenditures on the diagnosis and management exceeding $\$ 85$ billion. ${ }^{1,2}$ Both back and neck pain are independently in the top 5 diseases that contribute

This article was externally peer reviewed.

Submitted 3 January 2015; revised 1 March 2015; accepted 6 March 2015.

From the University of Michigan, Ann Arbor (MAD, OY); and the Dartmouth Institute for Health Policy and Clinical Practice, Dartmouth College, Geisel School of Medicine, Hanover, NH (MAD, DJG, JPWB).

Funding: This study was supported by award number K01AT006162 (to MAD) from the National Institutes of Health.

Conflict of interest: none declared.

Disclaimer: The National Institutes of Health had no role in the design and conduct of the study; collection, management, analysis, and interpretation of the data; preparation, review, or approval of the manuscript; and decision to submit the manuscript for publication. The views expressed herein do not necessarily represent the official vies of the National Institutes of Health.

Corresponding author: Matthew A. Davis, MPH, DC, PhD, University of Michigan, 400 North Ingalls, Ann Arbor, MI 48109 (E-mail: mattadav@umich.edu). to disability among Americans, outranking other diseases such as diabetes, chronic pulmonary disease, and ischemic heart disease. ${ }^{3}$ Expansion of the use of health care services for back and neck pain, and the projected increase in the Medicare-eligible population, in combination with expanded coverage of millions of Americans through the Affordable Care Act, have the potential to strain an already overstretched primary care physician (PCP) workforce.

Back pain is among the most common reason adults visit a primary care provider. ${ }^{4}$ While many individuals who experience back and/or neck pain initially visit a PCP, ${ }^{5}$ other types of services can potentially serve as a point of access to the health care system. ${ }^{6}$ In particular, adults with back and/or neck pain can seek chiropractic care without referral from a PCP. ${ }^{7}$ Currently, there are an estimated 75,000 chiropractors across the country practicing predominately in privately owned offices and clinics. $^{8}$ In the United States chiropractors are registered providers who participate in many state Med- 
icaid programs, most private health care insurances, and Medicare. ${ }^{7,9,10}$ National Medicare spending on chiropractic care has increased substantially in recent years: from $\$ 466$ million in 2006 to approximately $\$ 700$ million in 2011. ${ }^{11,12}$ Although chiropractic care has been a covered service since the 1970s, it has recently come under scrutiny by the Office of the Inspector General, ${ }^{11-14}$ and its merits are starting to be questioned by the general public. ${ }^{15}$

Missing from this debate is a discussion of how coverage of chiropractic care may affect the US health care system at large. Health services do not operate in a vacuum, and an understanding of how chiropractic care may affect use of medical care is imperative. A recent study found some evidence that chiropractors may locate in areas with higher PCP supply. ${ }^{8}$ Given that the supply of chiropractic care and PCP services may be positively correlated, important questions pertaining to the potential indirect effects of chiropractic care on PCP workload, simply by virtue of being located in the same areas, are raised. If chiropractic care is merely additive (ie, patients use chiropractic care in addition to medical services ${ }^{16,17}$ ), elimination of the benefit could save the system as much as $\$ 700$ million. If these 2 services are substitutable (specifically, if chiropractic care absorbs visits that would otherwise be made to local PCPs for back and/or neck pain), however, elimination of Medicare's chiropractic care benefit may shift those visits to primary care, with questionable costs savings. Moreover, this would add strain to an already overextended PCP workforce. ${ }^{18}$

Our study addresses this gap in the literature by examining whether chiropractic care affects use of PCP services among Medicare patients. The objectives of our study were (1) to examine the relationship between the supply of chiropractic care and PCP services across the US; (2) to determine whether there is any association between the supply of chiropractic care and the number of visits to PCPs for back and/or neck pain; and (3) to estimate the impact of chiropractic care on national spending related to $\mathrm{PCP}$ visits.

\section{Methods}

This study received an expedited institutional board review by the Committee for the Protection of Human Subjects at Dartmouth College in Hanover, $\mathrm{NH}$.

\section{Study Design and Data Source}

We used $100 \%$ US Medicare claims data to perform a cross-sectional study of the relationship between the regional supply of chiropractic care and the number of ambulatory visits to PCPs for back and/or neck pain. Our study used 2010 to 2011 data from the Center for Medicaid \& Medicare Services (CMS) National Provider Identifier (NPI), Part B Carrier, MedPar, Inpatient, and Outpatient files. ${ }^{10}$ Medicare data from 2010 were used to generate risk adjustment measures, and 2011 data were used to measure our independent and dependent variables.

First we identified all Medicare patients in the Carrier and Outpatient files (ie, those who had $\geq 1$ claim for ambulatory services) who were continuously enrolled from 2010 to 2011. Next, we restricted our sample of Medicare patients to those aged 66 to 99 years old as of January 1, 2011, and enrolled in both Medicare Part A and Part B (but not enrolled in Medicare Advantage). After these restrictions, our study population consisted of 17.7 million US adults.

\section{Measures}

\section{Supply of Chiropractic Care and PCP Services}

We used the NPI File to identify active chiropractors who were enrolled in the US Medicare program throughout 2011. To do so, we used provider specialty code 35 , which corresponds to Medicare provider type "Chiropractic." 19 Using this directory, we determined the practice location ZIP codes for chiropractors. We restricted our analyses to those who submitted $\geq 10$ Medicare Part B claims in 2011 to reduce the number of chiropractors who are enrolled in the Medicare program but are not actively treating patients. Practice location ZIP codes then were aggregated to the 306 hospital referral regions (HRRs) previously defined by the Dartmouth Atlas of Health Care..$^{20,21}$

For our study, we operationally defined a PCP enrolled with the US Medicare program as practicing internal medicine, family medicine, or general practice (Medicare specialty codes 11,08, and 01, respectively). ${ }^{19}$ As with chiropractors, we used the NPI file to identify PCPs listed as active (and their practice location), and we restricted our analyses to PCPs who submitted $\geq 10$ Medicare Part B claims in 2011. We also estimated separately the supply of PCPs for family medicine versus internal medicine. Because of the small number of providers 
who identified their specialty as general practice, we aggregated general practice with family medicine. To construct our measures of PCP supply, we calculated the number of active providers per 10,000 capita of Medicare patients residing in the respective HRR.

\section{Ambulatory Visits to PCPs for Back and/or Neck Pain}

To identify ambulatory visits to PCPs for back and/or neck pain, we used an established series of International Classification of Diseases, Ninth Revision (ICD-9) diagnosis codes in Medicare Part B claims that have been previously shown to capture the majority of these conditions. ${ }^{22}$ However, we excluded the ICD-9 diagnosis codes reserved for chiropractors (the 739 series for "Nonallopathic lesions" of the spine) for all analyses. We also excluded unallowed claims and duplicate claims for the same patient, provider, procedure, and date of service. A claim for an ambulatory visit can have multiple diagnosis codes; therefore, we identified the visit for back and/or neck pain if any of the corresponding ICD-9 codes $^{22}$ appeared anywhere on the claim for the ambulatory visit.

\section{Other Data}

We also collected data on sociodemographic characteristics for Medicare patients, including sex, race/ethnicity, rurality of residence (rural vs urban based on rural-urban commuting area codes), ${ }^{23}$ and age on January 1, 2011. Because patient morbidity likely varies depending on the subspecialty of the PCP (ie, family medicine vs internal medicine), we also constructed a Charlson comorbidity score based on all health care use in $2010 .{ }^{24}$ To do so, we identified both inpatient and outpatient health care use for specific conditions using Part B Carrier, MedPar, Inpatient, and Outpatient files.

\section{Statistical Analyses}

First, to examine whether supply of chiropractic care and PCP services are correlated, we examined associations using Spearman correlation according to US HRRs. We also examined this association separately by PCP specialty. To visualize supply of these services across the United States and any potential spatial patterns, we separated these distributions into quintiles and mapped them according to HRRs using ArcGIS software (ESRI, Redlands, CA).
Second, to examine the relationship between supply of chiropractic care and the number of visits to PCPs for back and/or neck pain, we used generalized linear models, adjusted for the supply of PCP services and patient characteristics. For these analyses, the unit of analysis was the individual patient and our dependent variable was the number of visits for the given patient to a PCP for back and/or neck pain in 2011. We assumed a Poisson distribution for the dependent variable in our models. To account for deviation in the distributional assumption of our models and for patient clustering within HRRs, we used a robust variance estimation method in all statistical models. The distribution of the supply of chiropractic care across HRRs, as defined above, was separated into quintiles representing the relative intensity of chiropractic care supply; quintiles were included in our models as fixed effects indicator variables, using the lowest quintile as the reference category.

Third, based on the above results, we estimated the national impact of chiropractic care on PCP visits and expenditures. To estimate current national spending on PCP services, we used the coefficients from our full models to predict the mean number of visits for back and/or neck pain according to the respective quintile of chiropractic care supply. The predicted mean number of visits for back and/or neck pain then was multiplied by the number of patients residing within the quintile to estimate the total visits. The total number of visits was further multiplied by the mean cost per visit in $2011(\$ 228)^{25}$ to estimate expenditure.

We used the lowest quintile to serve as an estimate of expenditures in the absence of chiropractic care (ie, to simulate visits and expenditures on PCP visits for back and/or neck pain without chiropractic care). Therefore, to estimate the impact of chiropractic care, we computed the differences between each of the quintiles compared with the lowest quintile of the supply of chiropractic care. As supply of chiropractic care is not zero in the lowest quintile, however, our estimates are likely conservative.

\section{Results}

\section{Patient Characteristics}

In 2011, among the 17.7 million older adults in our study population, 3.0 million made 5.9 million am- 


\begin{tabular}{|c|c|c|c|c|}
\hline & \multirow{2}{*}{$\begin{array}{c}\text { No PCP Visit for } \\
\text { Back and/or } \\
\text { Neck Pain }\end{array}$} & \multirow{2}{*}{$\begin{array}{c}\text { Visited any PCP for } \\
\text { Back and/or Neck } \\
\text { Pain }\end{array}$} & \multicolumn{2}{|c|}{$\begin{array}{l}\text { Visited for Back and/or Neck Pain, } \\
\text { By PCP Specialty }\end{array}$} \\
\hline & & & $\begin{array}{l}\text { Family Medicine } \\
\text { PCP }\end{array}$ & $\begin{array}{l}\text { Internal Medicine } \\
\text { PCP }\end{array}$ \\
\hline \multicolumn{5}{|l|}{ National estimates, $\mathrm{n}$ in millions } \\
\hline Patients & 14.7 & 3.0 & 1.4 & 1.7 \\
\hline Visits for back and/or neck pain & 0.0 & 5.9 & 2.7 & 3.2 \\
\hline $\begin{array}{l}\text { Estimated expenditures on back and/or neck } \\
\text { pain* }\end{array}$ & 0.0 & $1,345.2$ & 615.6 & 729.6 \\
\hline \multicolumn{5}{|l|}{ Patient characteristics } \\
\hline Mean age, years (SD) & $76.4(7.2)$ & $76.6(7.1)$ & $76.1(7.0)$ & $77.0(7.1)$ \\
\hline \multicolumn{5}{|l|}{ Sex, $\mathrm{n}$ in millions (\%) } \\
\hline Female & $8.5(57.7)$ & $2.0(65.1)$ & $0.9(64.1)$ & $1.1(66.2)$ \\
\hline Male & $6.2(42.3)$ & $1.1(34.9)$ & $0.5(35.9)$ & $0.6(33.8)$ \\
\hline \multicolumn{5}{|l|}{ Race, $\mathrm{n}$ in millions (\%) } \\
\hline Non-Hispanic white & $13.1(88.6)$ & $2.7(87.9)$ & $1.3(89.4)$ & $1.5(86.6)$ \\
\hline Non-Hispanic black & $1.0(6.8)$ & $0.2(6.4)$ & $0.1(5.5)$ & $0.1(7.0)$ \\
\hline Other & $0.7(4.6)$ & $0.2(5.6)$ & $0.1(5.0)$ & $0.1(6.3)$ \\
\hline Unknown & $0.0(0.1)$ & $0.0(0.1)$ & $0.0(0.1)$ & $0.0(0.1)$ \\
\hline \multicolumn{5}{|l|}{ Rurality of residence, $\mathrm{n}$ in millions (\%) } \\
\hline Urban & $8.5(57.9)$ & $1.8(59.1)$ & $0.7(50.2)$ & $1.1(66.6)$ \\
\hline Rural & $3.8(25.7)$ & $0.8(25.3)$ & $0.5(32.0)$ & $0.3(19.7)$ \\
\hline Unknown & $2.4(16.4)$ & $0.5(15.6)$ & $0.3(17.8)$ & $0.2(13.7)$ \\
\hline \multicolumn{5}{|l|}{ Charlson score, $\mathrm{n}$ in millions (\%) } \\
\hline 0 & $7.7(52.0)$ & $1.5(49.1)$ & $0.7(50.6)$ & $0.8(47.6)$ \\
\hline 1 & $2.4(16.5)$ & $0.5(16.7)$ & $0.2(16.7)$ & $0.3(16.7)$ \\
\hline 2 & $1.9(12.8)$ & $0.4(13.9)$ & $0.2(13.4)$ & $0.2(14.4)$ \\
\hline$\geq 3$ & $2.8(18.7)$ & $0.6(20.3)$ & $0.3(19.3)$ & $0.4(21.4)$ \\
\hline Unknown & $0.0(0.0)$ & $0.0(0.0)$ & $0.0(0.0)$ & $0.0(0.0)$ \\
\hline
\end{tabular}

All differences between those who did and did not visit any primary care physician (PCP) for back and/or neck pain are highly significant at $P<.001$; the $t$ test was used to compare means and the $\chi^{2}$ test was used to compare proportions.

${ }^{*}$ Calculated by multiplying total visits by estimated cost per visit of $\$ 228{ }^{26}$

PCP, primary care physician; SD, standard deviation.

bulatory visits to PCPs for back and/or neck pain (Table 1). Of these visits, 2.7 million were to family medicine physicians and 3.2 million were to internal medicine physicians. The mean age of Medicare patients who visited a PCP for back and/or neck pain was 76.6 years (standard deviation, 7.1 years), and patients who visited family medicine physicians were slightly younger than those who visited internal medicine physicians (mean age, 76.1 vs 77.0 years). Medicare patients who visited a PCP for back and/or neck pain were more likely to be female $(65.1 \%$ compared with $57.7 \%)$ and of poorer health status than those who did not visit a PCP for back and/or neck pain (eg, 20.3\% had a Charlson score of $\geq 3$ compared with $18.7 \%$ among those who did not visit a PCP for back and/or neck pain). By specialty, a higher percentage of patients from rural areas visited family medicine physicians (32\%) compared with internal medicine physicians $(19.7 \%)$.

\section{Supply of Chiropractic Care and PCP Services}

Across US HRRs, the number of chiropractors per 10,000 capita varied more than 17-fold (ranging from 3.1 to 54.7 per 10,000 capita). Likewise, the number of PCPs per 10,000 capita varied approximately 13-fold (ranging from 18.9 to 239.1 per 10,000 capita). The supply of family medicine physicians (ranging from 6.3 to 72.9 per 10,000 capita) was lower than the supply of internal medicine physicians (ranging from 7.9 to 199.6 per 10,000 capita). A visual examination of 2 density maps 
Figure 1. Supply of chiropractic care (A) and primary care physicians (B) according to US hospital referral regions. Supply is based on the number of active practitioners per 10,000 capita and separated into quintiles.
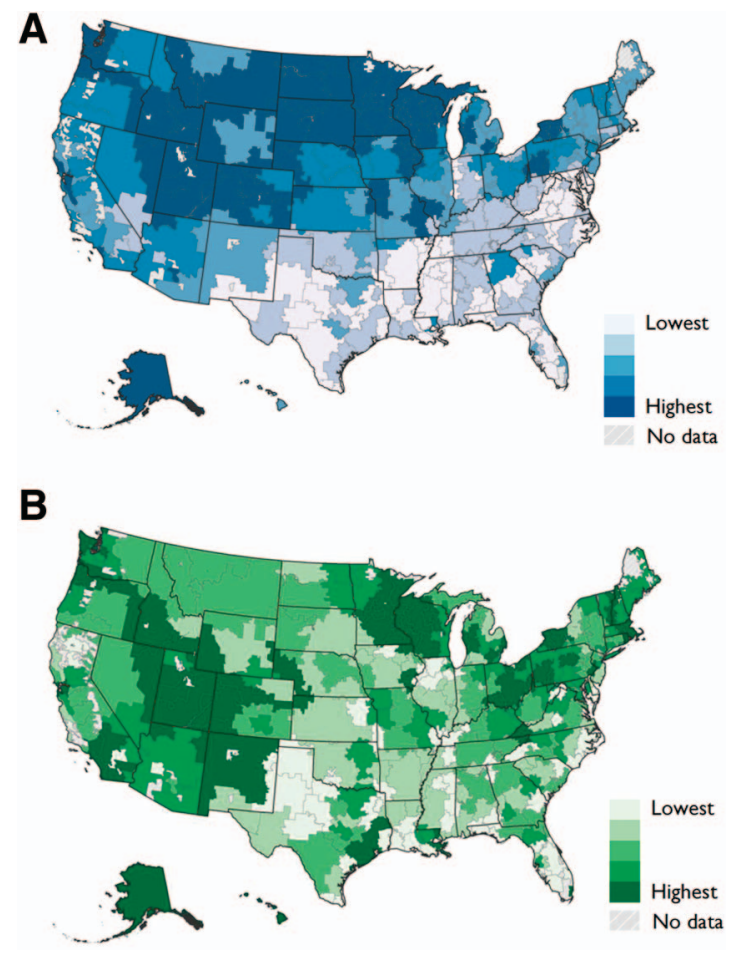

suggested that the 2 supplies are positively correlated overall, with the exception of the Midwest region, which was characterized by a relatively high observed supply of chiropractic care and relatively low supply of PCP services (Figure 1).
The supply of chiropractic care was positively correlated with the supply of PCP services; the Spearman correlation coefficient overall was 0.52 $(P<.001)$. Examined by PCP specialty, we found a stronger correlation between the supply of chiropractic care with family medicine than with internal medicine (Spearman correlation coefficient, 0.61 vs 0.30 , respectively; $P<.001$ for both) (Figure 2).

\section{Supply of Chiropractic Care and Visits to PCPs for Back and/or Neck Pain}

Adjusted for patient sociodemographic characteristics and comorbidity, an inverse association between the supply of chiropractic care and the number of annual visits to PCPs for back and/or neck pain was evident. The highest quintile of chiropractic care supply versus the lowest quintile was associated with $8 \%$ fewer visits to PCPs for back and/or neck pain (rate ratio [RR], 0.92; 95\% confidence interval, 0.91-0.92) (Table 2). Furthermore, there was an apparent trend across quintiles of fewer visits to PCPs for back or neck pain (RR, $1.08,0.98,0.97$, and 0.92 for quintiles 2 through 5, respectively; $P$ for trend $<.001)$. In analyses stratified by PCP specialty, a stronger association of chiropractic care supply and visits to family medicine was observed across quintiles. Residing in the highest quintile of chiropractic care supply, compared with the lowest quintile, was associated with a reduction of $15 \%$ and $10 \%$ in the number of visits for back and/or neck pain to family medicine and

Figure 2. Relationship between supply of chiropractic care and primary care physician (PCP) services according to US hospital referral regions.

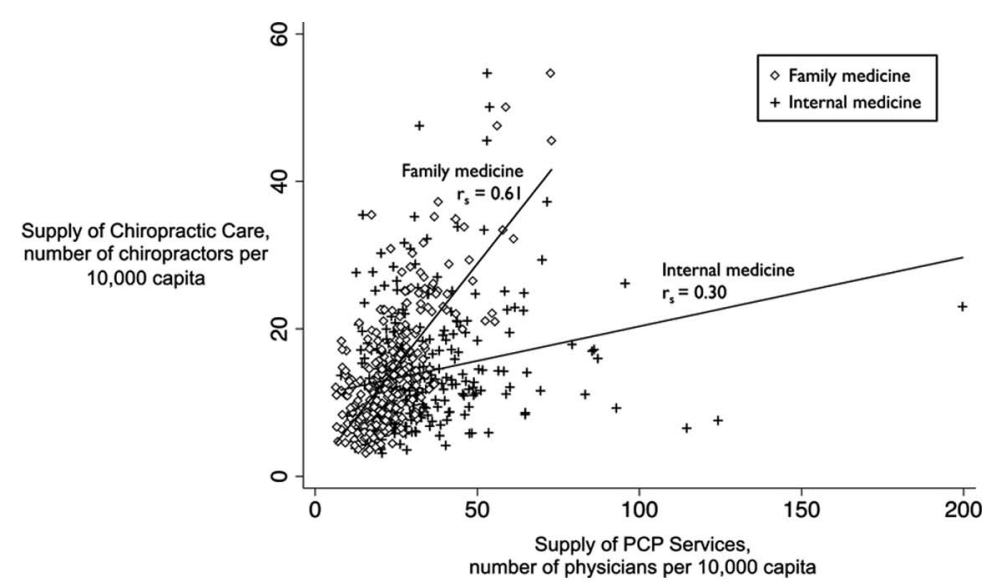

Spearman ranked correlation coefficient $\left(r_{\mathrm{s}}\right)$ was used to examine the association between the supply of chiropractic care and PCP services; both associations are highly significant at $P<.001$. 
Table 2. Adjusted Rate Ratios* (95\% Confidence Intervals) for the Association between Quintile of Chiropractic Care Supply and Annual Number of Visits to Primary Care Physicians for Back and/or Neck Pain

\begin{tabular}{|c|c|c|c|}
\hline \multirow[b]{2}{*}{ Independent Variable } & \multirow{2}{*}{$\begin{array}{l}\text { Visits to any PCP for } \\
\text { back and/or neck pain }\end{array}$} & \multicolumn{2}{|c|}{ Visits for Back and/or Neck Pain, By PCP Specialty } \\
\hline & & Family Medicine PCP & Internal Medicine PCP \\
\hline \multicolumn{4}{|l|}{ Supply of health services } \\
\hline \multicolumn{4}{|l|}{ Quintile of chiropractic care } \\
\hline 1 (lowest) & 1.00 (Reference) & 1.00 (Reference) & 1.00 (Reference) \\
\hline 2 & $1.08(1.07-1.09)$ & $1.07(1.06-1.08)$ & $1.08(1.07-1.09)$ \\
\hline 3 & $0.98(0.97-0.98)$ & $0.97(0.96-0.98)$ & $0.94(0.93-0.94)$ \\
\hline 4 & $0.97(0.97-0.98)$ & $0.86(0.86-0.86)$ & $1.02(1.01-1.02)$ \\
\hline 5 (highest) & $0.92(0.91-0.92)$ & $0.85(0.84-0.86)$ & $0.90(0.89-0.91)$ \\
\hline PCP services, ${ }^{\dagger}$ number per 10,000 & $1.00(1.00-1.00)$ & $1.02(1.02-1.02)$ & $1.01(1.01-1.01)$ \\
\hline \multicolumn{4}{|l|}{ Patient characteristics } \\
\hline Age, years & $1.00(0.99-1.00)$ & $0.99(0.99-0.99)$ & $1.01(1.00-1.01)$ \\
\hline \multicolumn{4}{|l|}{ Sex } \\
\hline Male & 1.00 (Reference) & 1.00 (Reference) & 1.00 (Reference) \\
\hline Female & $1.36(1.35-1.36)$ & $1.30(1.30-1.31)$ & $1.41(1.40-1.41)$ \\
\hline \multicolumn{4}{|l|}{ Race/ethnicity } \\
\hline Non-Hispanic white & 1.00 (Reference) & 1.00 (Reference) & 1.00 (Reference) \\
\hline Other & $1.11(1.10,-1.11)$ & $1.00(0.99-1.00)$ & $1.15(1.14-1.16)$ \\
\hline \multicolumn{4}{|l|}{ Rurality of residence } \\
\hline Urban & 1.00 (Reference) & 1.00 (Reference) & 1.00 (Reference) \\
\hline Rural & $0.99(0.99-0.99)$ & $1.39(1.38-1.40)$ & $0.72(0.71-0.72)$ \\
\hline \multicolumn{4}{|l|}{ Charlson Comorbidity Score } \\
\hline 0 & 1.00 (Reference) & 1.00 (Reference) & 1.00 (Reference) \\
\hline 1 & $1.13(1.12-1.13)$ & $1.10(1.09-1.11)$ & $1.15(1.14-1.16)$ \\
\hline 2 & $1.25(1.25-1.26)$ & $1.20(1.19-1.21)$ & $1.30(1.30-1.31)$ \\
\hline$\geq 3$ & $1.29(1.29-1.30$ & $1.22(1.21-1.24)$ & $1.35(1.34-1.35)$ \\
\hline
\end{tabular}

For each of the 3 models, $\mathrm{n}=14.9$ million Medicare patients.

*All rate ratios are highly significant at $P<.001$ (except for race/ethnicity) in predicting visits to family medicine physicians.

${ }^{\dagger}$ Variable used corresponds to primary care physician (PCP) specialty for the respective model (eg, for prediction of visits to family medicine PCPs, number of family medicine physicians per 10,000 capita was used).

internal medicine physicians, respectively (RR, 0.85 and 0.90 , respectively; Table 2).

\section{Estimated National Impact of Chiropractic Care on PCP Visits and Expenditures}

When extrapolated to the nation (based on our predictions from our adjusted model), we estimate that chiropractic care is associated with a reduction of 0.37 million visits to PCPs for back and/or neck pain at a total cost of $\$ 83.5$ million (Table 3).

\section{Discussion}

To our knowledge, this is one of the first studies to examine the association between chiropractic care and use of PCP services using national data. We found evidence to support previous findings that a higher supply of chiropractic care is correlated with PCP supply, ${ }^{8}$ suggesting the 2 services are located in similar areas. In this study, however, we found stronger associations between the 2 services (potentially because we removed inactive providers). By examining separately family medicine and internal medicine PCP supply, we also found evidence of an even stronger relationship between the supply of chiropractic care and family medicine.

In descriptive analyses a specific spatial pattern with a relatively higher concentration of chiropractic care in the Midwest and a lower concentration in the South was apparent. This finding is not surprising considering the chiropractic profession began in the Midwest (specifically in Davenport, Iowa, which had the highest supply of chiropractors of all HRRs). ${ }^{8,26,27}$ Given that the supply of physicians in general exhibits a different pattern, ${ }^{28}$ it may raise questions about the role of chiropractic care in improving access to care (particularly in 
Table 3. Estimated National Impact of Chiropractic Care on Annual Total Primary Care Physician (PCP) Visits and Expenditures for Back and/or Neck Pain

\begin{tabular}{|c|c|c|c|c|}
\hline \multirow[b]{2}{*}{$\begin{array}{l}\text { Quintile of Chiropractic } \\
\text { Care Supply }\end{array}$} & \multicolumn{2}{|c|}{ With Chiropractic Care* } & \multicolumn{2}{|c|}{$\begin{array}{c}\text { Estimated Difference Without } \\
\text { Chiropractic Care }\end{array}$} \\
\hline & $\begin{array}{l}\text { Visits to PCPs for Back and/or } \\
\text { Neck Pain }\end{array}$ & $\begin{array}{c}\text { Expenditures on PCP } \\
\text { Visits for Back and/or } \\
\text { Neck Pain }\end{array}$ & $\begin{array}{c}\text { Visits to PCPs for } \\
\text { Back and/or Neck } \\
\text { Pain }\end{array}$ & $\begin{array}{c}\text { Expenditures on PCP } \\
\text { Visits for Back and/or } \\
\text { Neck Pain }\end{array}$ \\
\hline 1 (Lowest) & 1.21 & 275.6 & Reference & Reference \\
\hline 2 & 1.07 & 243.7 & -0.14 & -31.9 \\
\hline 3 & 1.20 & 274.6 & -0.01 & -1.0 \\
\hline 4 & 1.11 & 252.9 & -0.10 & -22.7 \\
\hline 5 (Highest) & 1.09 & 247.7 & -0.12 & -27.9 \\
\hline Total & & & -0.37 & -83.5 \\
\hline
\end{tabular}

*Estimates are based on predictions from the model adjusted for covariates in Table 2.

${ }^{\dagger}$ Estimated by comparing with quintile 1 (as a measure of very low chiropractic care supply).

rural locales). Previous studies have examined the potential role of chiropractic care in improving access to care. ${ }^{29,30}$

Most important, we found some modest evidence that areas with a greater supply of chiropractic care are associated with patients having fewer visits to PCPs for back and/or neck pain (and more so for visits to family medicine physicians). Residing in an area with the highest quintile of chiropractic care supply compared with the lowest was associated with $8 \%$ fewer annual ambulatory visits to PCPs for back and/or neck pain (a difference associated with an estimated national decrease of 0.12 million visits; Table 3). While this potential reduction seems small, considering the high prevalence and cost associated with back and/or neck pain, further study may be warranted. An interesting finding that we cannot yet fully explain is the apparent relative increase in the number of visits to PCPs in quintile 2 compared with quintile 1 ; residing in quintile 2 compared with quintile 1 was associated with an increase of $8 \%$ for visits for back and/or neck pain. A potential explanation could be that when the supply of chiropractic care is nonnegligible, as it is in quintile 1 , a chiropractic presence in the market may lead to differences in how frequently people seek treatment for back and/or neck pain because of advertising or other factors.

While our study is among the first to examine the potential indirect effects of chiropractic care on visits to PCPs for back and/or neck pain, previous studies have compared the costs of health services among private insurance beneficiaries with and without a chiropractic care benefit. ${ }^{31-34}$ Collectively, these studies suggest that coverage of chiropractic care among adults is associated with reduced spending on medicine and use of diagnostic tests in the population with private insurance. Among the Medicare population, chiropractic care may be beneficial in improving functional status among older adults. ${ }^{35-37}$ A provoking finding was that $<10 \%$ of chiropractic users also use other medical services for the same episode of care. ${ }^{38}$ There is some evidence that individuals become accustomed to seeking chiropractic care, possibly because of lower satisfaction with medical care. ${ }^{37,39,40}$ Our findings may indicate that chiropractic care may be used as a substitute for (rather than in addition to) medical care.

When extrapolating these estimates to the nation, we estimate that chiropractic care may reduce the number of visits that would have otherwise be made to PCPs for back and/or neck pain by 0.37 million, at a cost of $\$ 83.5$ million per year. While this total amount is not trivial, it is substantially smaller than the annual estimated cost of the chiropractic care benefit (approximately $\$ 700$ million). ${ }^{11,12}$ Nevertheless, this estimate does not account for any potential effects on other medical services such as specialty care or diagnostic imaging. The evidence for potential substitution of PCP services with chiropractic care (and potential cost savings associated therewith) should be considered when evaluating the overall value of Medicare's chiropractic care benefit.

There are several limitations of our study that must be acknowledged. First, our study was a crosssectional design, and we therefore cannot establish a causal relationship between the supply of chiropractic care and visits to PCPs for back and/or neck pain; more rigorous, prospective designs are required to do so. Second, while we adjusted for 
patient sociodemographic factors, comorbidity, and the supply of PCPs in our models, we cannot rule out the potential effect of residual confounding (such as differences in the complexity of back and/or neck pain treated by physicians vs chiropractors) on the associations we observed. Third, our study population was limited to older adults enrolled in Medicare from 2010 to 2011. While this limits the generalizability of our findings, it does make the results of our study directly applicable to informing CMS policy. Fourth, using claims data, it is not possible to definitively determine the primary reason for a health care visit. As done in other studies, we identified ambulatory visits to PCPs for back and/or neck pain if a back or neck pain ICD-9 diagnosis code appeared anywhere on the claim; being more inclusive rather than exclusive may have overestimated visits that were primarily for back and/or neck pain. ${ }^{1,2,6,22}$ Last, our study was limited to studying the effects on ambulatory PCP workload and neglected to consider effects on other types of services such as specialty care and diagnostic services. Our future work will examine the potential impact of chiropractic care on these and other medical services using more rigorous study designs.

Despite the inherent limitations of our study, our findings offer important insights into the indirect effects of Medicare's chiropractic care benefit on PCP services. Our finding that chiropractic care is associated with fewer visits to PCPs for back and/or neck pain is important for health policymakers to consider. Driven by both increased spending ${ }^{11,12}$ and a series of reports by the Office of the Inspector General, ${ }^{11-14}$ Medicare's chiropractic care benefit is currently being examined. In addition to providing important information regarding the impact of coverage of chiropractic care, our study also underscores the importance of evaluating the indirect effects of ambulatory health services.

The authors thank Heather Carlos, GeoSpatial Resource Center at Norris Cotton Cancer Center, Dartmouth-Hitchcock Medical Center, for assistance with spatial analyses.

\section{References}

1. Martin BI, Deyo RA, Mirza SK, et al. Expenditures and health status among adults with back and neck problems. JAMA 2008;299:656-64.
2. Martin BI, Turner JA, Mirza SK, Lee MJ, Comstock BA, Deyo RA. Trends in health care expenditures, utilization, and health status among US adults with spine problems, 1997-2006. Spine (Phila Pa 1976) 2009;34:2077-84.

3. Murray CJ, Atkinson C, Bhalla K, et al; US Burden of Disease Collaborators. The state of US health, 1990-2010: burden of diseases, injuries, and risk factors. JAMA 2013;310:591-608.

4. Hart LG, Deyo RA, Cherkin DC. Physician office visits for low back pain. Frequency, clinical evaluation, and treatment patterns from a U.S. national survey. Spine (Phila Pa 1976) 1995;20:11-9.

5. Deyo RA, Jarvik JG, Chou R. Low back pain in primary care. BMJ 2014;349:g4266.

6. Davis MA, Onega T, Weeks WB, Lurie JD. Where the United States spends its spine dollars: expenditures on different ambulatory services for the management of back and neck conditions. Spine (Phila Pa 1976) 2012;37:1693-701.

7. Meeker WC, Haldeman S. Chiropractic: a profession at the crossroads of mainstream and alternative medicine. Ann Intern Med 2002;136:216-27.

8. Davis MA, Mackenzie TA, Coulter ID, Whedon JM, Weeks WB. The United States Chiropractic Workforce: an alternative or complement to primary care? Chiropr Man Therap 2012;20:35.

9. Steyer TE, Freed GL, Lantz PM. Medicaid reimbursement for alternative therapies. Altern Ther Health Med 2002;8:84-8.

10. Whedon JM, Song Y, Davis MA. Trends in the use and cost of chiropractic spinal manipulation under Medicare Part B. Spine J 2013;13:1449-54.

11. Office of the Inspector General. Inappropriate Medicare payments for chiropractic services. Washington, DC: US Department of Health and Human Services; 2009. Available from: https://oig.hhs.gov/ oei/reports/oei-07-07-00390.pdf. Accessed May $11,2015$.

12. US Department of Health and Human Services, Office of the Inspector General. Audit (A-09-1202072). Diep Chiropractic Wellness, Inc., received unallowable Medicare payments for chiropractic services. Washington, DC: US Department of Health and Human Services; 2013. Available from: https:// oig.hhs.gov/oas/reports/region9/91202072.asp. Accessed May 11, 2015.

13. Office of the Inspector General. Chiropractic services in the Medicare program: payment vulnerability analysis. Washington, DC: US Department of Health and Human Services; 2005. Available from: https://oig.hhs.gov/oei/reports/oei-09-0200530.pdf. Accessed May 11, 2015.

14. Office of the Inspector General. Work plan for fiscal year 2014. Washington, DC: US Department of Health and Human Services; 2014. Available from: http://oig.hhs.gov/reports-and-publications/archives/ 
workplan/2014/Work-Plan-2014.pdf. Accessed May 11, 2015.

15. Salzberg S. New Medicare data reveal startling $\$ 496$ million wasted on chiropractors. April 20, 2014. Available from: http://www.forbes.com/sites/stevensalzberg/ 2014/04/20/new-medicare-data-reveal-startling496-million-wasted-on-chiropractors/. Accessed November 14, 2014.

16. Astin JA. Why patients use alternative medicine: results of a national study. JAMA 1998;279:1548-53.

17. Davis MA, West AN, Weeks WB, Sirovich BE. Health behaviors and utilization among users of complementary and alternative medicine for treatment versus health promotion. Health Serv Res 2011;46:1402-16.

18. Bodenheimer TS, Smith MD. Primary care: proposed solutions to the physician shortage without training more physicians. Health Aff (Millwood) 2013;32:1881-6.

19. Center for Medicare \& Medicaid Services. Crosswalk: Medicare provider/supplier to healthcare provider taxonomy. January 22, 2015. Available from: http://www.cms.gov/Medicare/ProviderEnrollment-and-Certification/MedicareProvider SupEnroll/Downloads/TaxonomyCrosswalk.pdf. Accessed March 11, 2015.

20. Fisher ES, Wennberg DE, Stukel TA, Gottlieb DJ, Lucas FL, Pinder EL. The implications of regional variations in Medicare spending. Part 2: health outcomes and satisfaction with care. Ann Intern Med 2003;138:288-98.

21. Fisher ES, Wennberg DE, Stukel TA, Gottlieb DJ, Lucas FL, Pinder EL. The implications of regional variations in Medicare spending. Part 1: the content, quality, and accessibility of care. Ann Intern Med 2003; 138:273-87.

22. Cherkin DC, Deyo RA, Volinn E, Loeser JD. Use of the International Classification of Diseases (ICD-9$\mathrm{CM}$ ) to identify hospitalizations for mechanical low back problems in administrative databases. Spine (Phila Pa 1976) 1992;17:817-25.

23. WWAMI Rural Health Research Center. Rural-urban commuting area codes. Available from: http:// depts.washington.edu/uwruca/. Accessed November 14, 2014.

24. Deyo RA, Cherkin DC, Ciol MA. Adapting a clinical comorbidity index for use with ICD-9-CM administrative databases. J Clin Epidemiol 1992;45:613-9.

25. Agency for Healthcare Research and Quality. Medical Expenditure Panel Survey. MEPSnet/HC Trend Query. 2014. Washington, DC: US Department of Health and Human Services. Updated November 10, 2014. Available from: http://meps.ahrq.gov/ mepsweb/data_stats/MEPSnetHC/startup. Accessed November 14, 2014.

26. Peregoy JA, Clarke TC, Jones LI, Stussman BJ, Nahin RL. Regional variation in use of complemen- tary health approaches by U.S. adults. NCHS Data Brief 2014;(146):1-8.

27. Whedon JM, Song Y, Davis MA, Lurie JD. Use of chiropractic spinal manipulation in older adults is strongly correlated with supply. Spine (Phila $\mathrm{Pa}$ 1976) 2012;37:1771-7.

28. Goodman DC BS, Chang C, Fisher ES. The Dartmouth atlas of health care. Regional and racial variation in primary care and the quality of care among Medicare beneficiaries. Hanover, NH: The Dartmouth Institute for Health Policy and Clinical Practice; 2010.

29. Smith M, Carber L. Chiropractic health care in health professional shortage areas in the United States. Am J Public Health 2002;92:2001-9.

30. Smith M, Carber LA. Chiropractors as safety net providers: first report of findings and methods from a US survey of chiropractors. J Manipulative Physiol Ther 2007;30:718-28.

31. Metz RD, Nelson CF, LaBrot T, Pelletier KR. Chiropractic care: is it substitution care or add-on care in corporate medical plans? J Occup Environ Med 2004;46:847-55.

32. Nelson CF, Metz RD, LaBrot T. Effects of a managed chiropractic benefit on the use of specific diagnostic and therapeutic procedures in the treatment of low back and neck pain. J Manipulative Physiol Ther 2005;28:564-9.

33. Nelson CF, Metz RD, LaBrot TM, Pelletier KR. The selection effects of the inclusion of a chiropractic benefit on the patient population of a managed health care organization. J Manipulative Physiol Ther 2005;28:164-9.

34. Legorreta AP, Metz RD, Nelson CF, Ray S, Chernicoff HO, Dinubile NA. Comparative analysis of individuals with and without chiropractic coverage: patient characteristics, utilization, and costs. Arch Intern Med 2004;164:1985-92.

35. Weigel PA, Hockenberry J, Bentler S, Wolinsky FD. Chiropractic use and changes in health among older medicare beneficiaries: a comparative effectiveness observational study. J Manipulative Physiol Ther 2013;36:572-84.

36. Weigel PA, Hockenberry J, Bentler SE, Wolinsky FD. The comparative effect of episodes of chiropractic and medical treatment on the health of older adults. J Manipulative Physiol Ther 2014;37:143-54.

37. Weigel PA, Hockenberry JM, Wolinsky FD. Chiropractic use in the medicare population: prevalence, patterns, and associations with 1-year changes in health and satisfaction with care. J Manipulative Physiol Ther 2014;37:542-51.

38. Weigel PA, Hockenberry JM, Bentler SE, Kaskie B, Wolinsky FD. Chiropractic episodes and the co- 
occurrence of chiropractic and health services use among older Medicare beneficiaries. J Manipulative Physiol Ther 2012;35:168-75.

39. Hertzman-Miller RP, Morgenstern H, Hurwitz EL, et al. Comparing the satisfaction of low back pain patients randomized to receive medical or chiropractic care: results from the UCLA low-back pain study. Am J Public Health 2002;92:1628-33.

40. McPhillips-Tangum CA, Cherkin DC, Rhodes LA, Markham C. Reasons for repeated medical visits among patients with chronic back pain. J Gen Intern Med 1998;13:289-95. 